\title{
High-throughput screen of essential gene modules in Mycobacterium tuberculosis: a bibliometric approach
}

\author{
Guangyu Xu ${ }^{1}$, Bin Liư ${ }^{2}$, Fang Wang ${ }^{1}$, Chengguo Wei ${ }^{1}$, Ying Zhang ${ }^{1}$, Jiyao Sheng ${ }^{1}$, Guoqing Wang ${ }^{1 *}$ and Fan $\mathrm{Li}^{i^{*}}$
}

\begin{abstract}
Background: Tuberculosis (TB) is an infectious disease caused by Mycobacterium tuberculosis (M. tuberculosis). The annotation of functional genome and signaling network in M. tuberculosis are still not systematic. Essential gene modules are a collection of functionally related essential genes in the same signaling or metabolic pathway. The determination of essential genes and essential gene modules at genomic level may be important for better understanding of the physiology and pathology of M. tuberculosis, and also helpful for the development of drugs against this pathogen. The establishment of genomic operon database (DOOR) and the annotation of gene pathways have felicitated the genomic analysis of the essential gene modules of M. tuberculosis.

Method: Bibliometric approach has been used to perform a High-throughput screen for essential genes of $M$. tuberculosis strain H37Rv. Ant colony algorithm were used to identify the essential genes in other M. tuberculosis reference strains. Essential gene modules were analyzed by operon database DOOR. The pathways of essential genes were assessed by Biocarta, KEGG, NCI-PID, HumanCyc and Reactome. The function prediction of essential genes was analyzed by Pfam.
\end{abstract}

Results: A total approximately 700 essential genes were identified in M. tuberculosis genome. 40\% of operons are consisted of two or more essential genes. The essential genes were distributed in 92 pathways in M. tuberculosis. In function prediction, $61.79 \%$ of essential genes were categorized into virulence, intermediary metabolism/respiration, cell wall related and lipid metabolism, which are fundamental functions that exist in most bacteria species.

Conclusion: We have identified the essential genes of M. tuberculosis using bibliometric approach at genomic level. The essential gene modules were further identified and analyzed.

Keywords: Mycobacterium tuberculosis, Essential gene modules, Operon, Pathway

\section{Introduction}

Tuberculosis (TB) is an infectious disease caused by Mycobacterium tuberculosis (M. tuberculosis) [1,2]. In recent years, the prevention and treatment of TB have become difficult due to the prevalence of co-infection with HIV, drug resistance and uncertainty of Bacillus Calmette-Gu érin (BCG) prevention [3-5]. Essential genes are those genes required for cell growth and survival [6,7]. Previous studies on the essential genes of $M$. tuberculosis pathogenesis primarily using gene knockout or RNA interfe-

\footnotetext{
* Correspondence: qing@jlu.edu.cn; lifan@jlu.edu.cn

${ }^{1}$ Key Laboratory of Zoonosis, Ministry of Education, Norman Bethune College of Medicine, Jilin University, Changchun, Jilin, China

Full list of author information is available at the end of the article
}

rence [8]. This approach is expensive and inefficient, and due to limitations of experimental techniques, no experimental method can achieve an essential gene screen at a High-throughput level $[9,10]$. Essential gene modules are a collection of functionally related essential genes in the same signaling or metabolic pathway [11]. The determination of essential genes and essential gene modules at genomic level may be important for better understanding of the physiology and pathology of M. tuberculosis, and also helpful for the development of drugs against this pathogen.

To date, more than 31 genomes of Mycobacterium spp. have been sequenced including nine $M$. tuberculosis strains [12]. However, the systematic analysis of functional genomics and metabolic regulation were not established



(c) 2013 Xu et al.; licensee BioMed Central Ltd. This is an Open Access article distributed under the terms of the Creative Commons Attribution License (http://creativecommons.org/licenses/by/2.0), which permits unrestricted use, distribution, and reproduction in any medium, provided the original work is properly cited. 
in M. tuberculosis. In this study, we used a bibliometric approach and performed a High-throughput screening of five $M$. tuberculosis strains to identify the essential genes. We further analyzed the essential operons and pathways, based on early-established genomic operon database and annotation of gene locus [13-15].

\section{Material and methods}

\section{Bibliometric method}

The bibliometric was used as previously described [16]. The keywords "Mycobacterium tuberculosis" "H37Rv" "essential gene" have been used to search the publications from 2002 to 2011 in PubMed, MEDLINE, BiosisPreview, EMbase and SciFinder. Using Epidata3.1, the duplications of literatures and unrelated literatures were deleted by parallel entry and logical error test. A total of 819 literatures were retrieved and 112 literatures were used to analysis the essential gene modules.

\section{Ant colony algorithm}

Multiple sequence alignment bases on BLAST algorithm was restricted by the length and number of the sequences. So, in this study, we used ant colony algorithm to optimize it $[17,18]$. First, we divided all sequences into several parts and gain an initial population of $K$ as a column, $\mathrm{N}$ as a row. $\mathrm{K}$ is the number of individuals of the K-substituting groups; $\mathrm{N}$ is the number of sequences. $\mathrm{d}_{\mathrm{ij}}$ indicates the $\mathrm{i}^{\text {th }}$ individual dividing positions on the $\mathrm{j}^{\text {th }}$ sequence. For the array, the calculation formula of fitness( $r$ ) is as follow:

$$
\begin{aligned}
\operatorname{fitness}(r)= & \sum_{i=1}^{N-1} \sum_{j=i+1}^{N} S E\left(S_{i}^{p}\left(d_{r i}\right), S_{j}^{p}\left(d_{r i}\right)\right) \\
& +\sum_{i=1}^{N-1} \sum_{j=i+1}^{N} S E\left(S_{i}^{S}\left(d_{r i}\right), S_{j}^{S}\left(d_{r i}\right)\right)
\end{aligned}
$$

The following parameters were used for analysis: the Initial $=5, \mathrm{~d}_{1}=2, \mathrm{~d}_{2}=2, \mathrm{~d}_{3}=3, \mathrm{NCmax}$ (The maximum number of iterations $)=100, \mathrm{~m}$ (number of ants $)=100$; Parameters for information volatile degree are $\mathrm{p}=0.05$, $\mathrm{q}=0.03, \mathrm{q}_{1}=0.6, \mathrm{q}_{2}=0.35, \mathrm{q} 3=0.2, \mathrm{a}=5, \mathrm{~b}=3, \mathrm{c}=2$, $\mathrm{T}_{1}=50, \mathrm{~T}_{2}=79, \mathrm{~T}_{3}=99, \mathrm{Q}_{1}=0.1, \mathrm{Q}_{2}=0.2$.

\section{Results}

\section{Operons and pathways of screened essential genes in M. tuberculosis strains}

The genome of the highly pathogenic M. tuberculosis strain H37Rv has been sequenced [19]. Using bibliometric analysis, 684 essential genes were identified in $\mathrm{H} 37 \mathrm{Rv}$ strain, 617 genes were proved by experiments as well as 67 genes were identified using an in silico approach. (Related literature of these genes listed in Additional file 1: Table S1). These genes were evenly distributed in the genome, consistent with the previous study [20]. The genomes of $M$. tuberculosis among the five strains (H37Rv, H37Ra, CDC1511, F11, and KZN1435) were highly conserved. Therefore, we searched the Gene Bank (http:// www.ncbi.nlm.nih.gov/genbank) using ant colony algorithm to look for essential genes of other reference strains (H37Ra, CDC1511, F11, and KZN1435). The essential genes of these strains were 702, 665, 699 and 697, respectively (Table 1). It was worth noting that the number of essential genes in the different strains are varies, although the genomes of $M$. tuberculosis are highly conserved. This phenomenon is mainly caused by the total number of genes in each stain are different, and some essential gene will divide into two genes in another genome, which caused the differences of essential genes.

We used operon database (DOOR) to assess the essential gene modules. These essential genes were fallen in 307, 326, 297, 310 and 316 operons in H37Rv, H37Ra, CDC1511, F11 and KZN1435, respectively (Table 1). Statistical analysis showed that there is no relationship between the size of the operon and the number of essential genes identified. In all strains, approximately $40 \%$ of operons are consisted of two or more essential genes and some operons controlled more than ten genes, suggesting that these operons may play an important role in physiology or pathogenesis. For example, the operon ID7843 controls eleven genes, nine of which are essential genes (Figure 1A). Of them, five genes are related to cell membrane, two genes encode protein related to PE/PPE family and another two genes encode hypothetical proteins.

Pathway is a signal transduction network that involves in multiple gene interaction. We analyzed the essential genes using pathway databases Biocarta, KEGG, NCI-PID, HumanCyc and Reactome. Although the numbers of essential genes in the five strains are slightly different, these essential genes have the same number of pathways (Table 1). The 684 essential genes of the $\mathrm{H} 37 \mathrm{Rv}$ strain were distributed in 92 pathways. Of them, seven pathways only have one essential gene; 82 pathways have less than 50 essential genes; three pathways have more than 50 essential genes. It is interesting to note that in a portion of the pathway is entirely constituted by essential genes, which adjacent to each other in the genome. Histidine metabolism pathway, which is related to intermediary metabolism and respiratory, involves in ten essential genes. Seven of them are adjacent to each other and these clustered genes (Rv1599-1606) are required for L-histidine synthesis [21] (Figure 1B). Peptidoglycan synthesis pathway, which is related to cell wall and membrane formation, involves in ten essential genes (Figure 1C). Five essential genes $(R v 2152-2157)$ are clustered together in the genome. Two of them are involved in N-acetyl muramic acid synthesis and the others for uridine monophosphate (UMP) synthesis [22]. We speculated that 
Table 1 Essential genes, operons and pathway in reference strains H37Rv, H37Ra, CDC1511, F11, KZN1435

\begin{tabular}{|c|c|c|c|c|c|c|}
\hline \multirow[b]{2}{*}{ Strains } & \multirow[b]{2}{*}{$\begin{array}{l}\text { Essential } \\
\text { genes }\end{array}$} & \multicolumn{2}{|c|}{ Operons } & \multicolumn{3}{|c|}{ Pathways } \\
\hline & & $\begin{array}{c}\text { Contain } 1 \\
\text { essential gene }\end{array}$ & $\begin{array}{c}\text { Contain more than } 2 \\
\text { essential genes }\end{array}$ & $\begin{array}{c}\text { Contain } 1 \\
\text { essential gene }\end{array}$ & $\begin{array}{l}\text { Contain less than } 50 \\
\text { essential genes }\end{array}$ & $\begin{array}{c}\text { Contain more than } 50 \\
\text { essential genes }\end{array}$ \\
\hline H37Rv & 684 & 185(60\%) & $122(40 \%)$ & $7(8 \%)$ & $82(89 \%)$ & $3(3 \%)$ \\
\hline H37Ra & 702 & 192(59\%) & 134(41\%) & $7(8 \%)$ & 82(89\%) & $3(3 \%)$ \\
\hline CDC1551 & 665 & $178(60 \%)$ & 119(40\%) & 7(8\%) & 82(89\%) & $3(3 \%)$ \\
\hline F11 & 699 & $186(60 \%)$ & $124(40 \%)$ & $7(8 \%)$ & 82(89\%) & $3(3 \%)$ \\
\hline KZN1435 & 697 & 185(59\%) & $131(41 \%)$ & $7(8 \%)$ & $82(89 \%)$ & $3(3 \%)$ \\
\hline
\end{tabular}



\section{B Histidine metabolism}

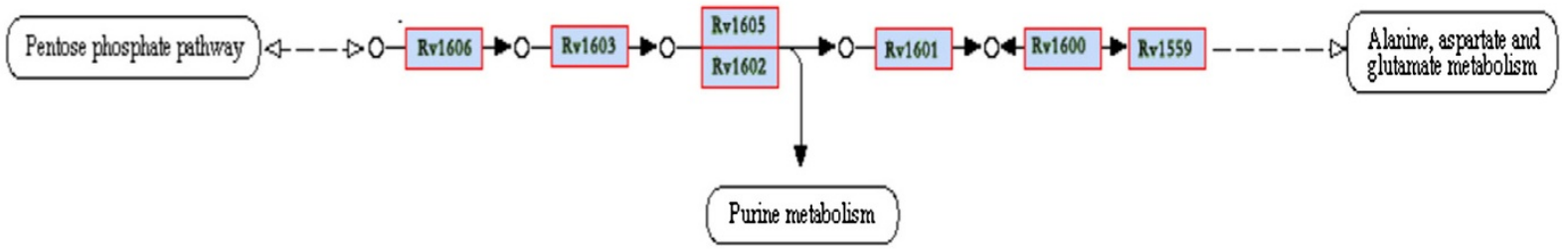

\section{Peptidoglycan biosynthesis}

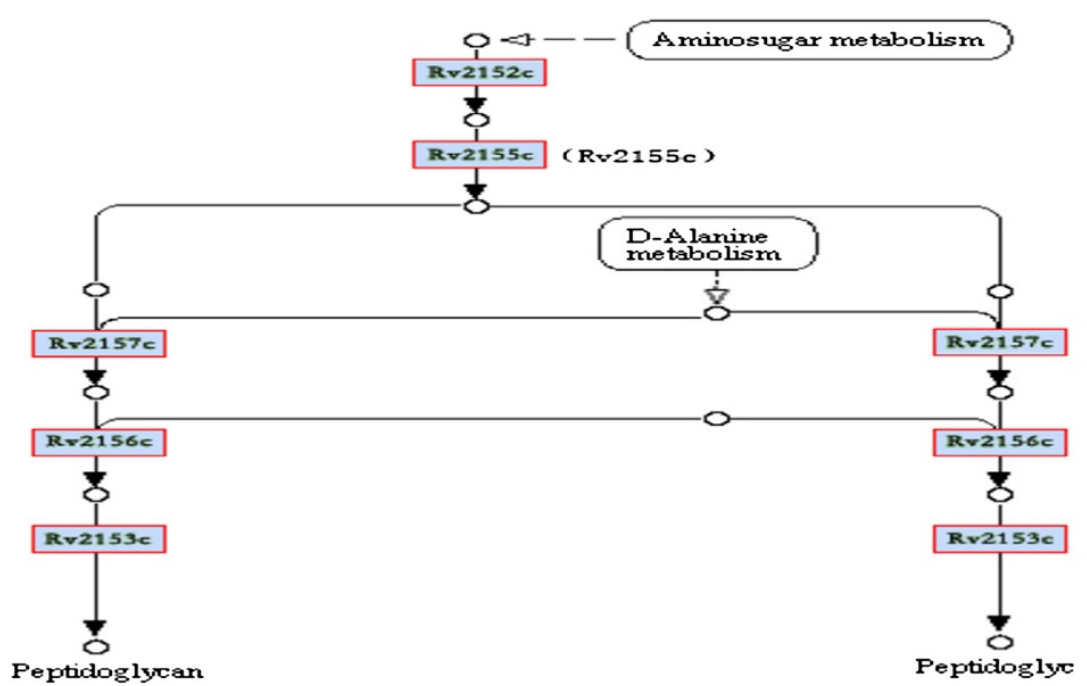

Figure 1 Essential gene modules operons and pathways. (A) An illustration for operon 7843. Non-essential genes are marked in red; PE/PPE family related genes are marked in green; possible conserved membrance genes are marked in yellow; hypothetical protein are marked in blue. (B) An illustration for histidine metabolism pathway. (C) An illustration for petidoglycan biosynthesis pathway. 
Table 2 Function predictions of essential genes for reference strains H37Rv, H37Ra, CDC1511, F11, KZN1435

\begin{tabular}{|c|c|c|c|c|c|}
\hline & H37Rv & H37Ra & CDC1551 & F11 & KZN1435 \\
\hline \multirow[t]{2}{*}{ Replication } & 10 & 10 & 10 & 10 & 10 \\
\hline & $(0.01 \%)$ & $(0.01 \%)$ & $(0.02 \%)$ & $(0.01 \%)$ & $(0.01 \%)$ \\
\hline \multirow[t]{2}{*}{ Regulatory proteins } & 10 & 10 & 10 & 10 & 10 \\
\hline & $(0.01 \%)$ & $(0.01 \%)$ & $(0.02 \%)$ & $(0.01 \%)$ & $(0.01 \%)$ \\
\hline \multirow[t]{2}{*}{ Virulence } & 288 & 293 & 284 & 292 & 291 \\
\hline & $(42.10 \%)$ & $(41.74 \%)$ & $(42.71 \%)$ & $(41.77 \%)$ & $(41.75 \%)$ \\
\hline \multirow[t]{2}{*}{ Intermediary metabolism and respiration } & 265 & 270 & 260 & 269 & 266 \\
\hline & $(38.74 \%)$ & $(38.46 \%)$ & (39.10\%) & $(38.48 \%)$ & $(38.16 \%)$ \\
\hline \multirow[t]{2}{*}{ Cell wall related } & 297 & 302 & 295 & 302 & 299 \\
\hline & $(43.42 \%)$ & $(43.021 \%)$ & $(44.36 \%)$ & $(43.20 \%)$ & (42.90\%) \\
\hline \multirow[t]{2}{*}{ information pathway } & 251 & 255 & 248 & 256 & 253 \\
\hline & (36.70\%) & $(36.32 \%)$ & $(37.29 \%)$ & $(36.62 \%)$ & (36.30\%) \\
\hline \multirow[t]{2}{*}{ Lipid metabolism } & 257 & 263 & 254 & 263 & 260 \\
\hline & $(37.57 \%)$ & $(37.46 \%)$ & (38.20\%) & $(37.63 \%)$ & (37.30\%) \\
\hline \multirow[t]{2}{*}{ PE/PPE family } & 11 & 14 & 8 & 14 & 13 \\
\hline & $(0.02 \%)$ & $(0.02 \%)$ & $(0.01 \%)$ & $(0.02 \%)$ & $(0.02 \%)$ \\
\hline \multirow[t]{2}{*}{ Insertion seqs and phages } & 12 & 13 & 10 & 13 & 12 \\
\hline & $(0.02 \%)$ & $(0.02 \%)$ & $(0.02 \%)$ & $(0.02 \%)$ & $(0.02 \%)$ \\
\hline \multirow[t]{2}{*}{ Hypothetical/unknown } & 261 & 269 & 255 & 269 & 268 \\
\hline & (38.15\%) & (38.31\%) & (38.35\%) & (38.48\%) & $(38.45 \%)$ \\
\hline
\end{tabular}

the linked genes are required for proper function and play crucial roles in pathways.

\section{Function prediction of essential genes in M. tuberculosis} We used Pfam (http://pfam.sanger.ac.uk/) to predict the potential function of the essential genes by analyzing the functional domains of encoded proteins. The functions of the essential genes are categorized into replication, regulatory proteins, virulence, intermediary metabolism and respiration, cell wall related, signal pathways, lipid metabolism, PE/PPE family, insertion sequences/phages and unknown (Table 2). 61.79\% of essential genes are fallen into virulence, intermediary metabolism/respiration, cell wall related, signal pathways and lipid metabolism. $0.06 \%$ of essential genes are fallen into replication, regulatory proteins, PE/PPE family, and insertion sequences/phages; $38.15 \%$ of essential genes into unknown.

\section{Discussion}

In the current study, we have done a High-throughput screen for essential genes of $M$. tuberculosis. A total approximately 700 essential genes are identified in the genome, some genes were proved by experiments as well as some genes were identified using an in silico approach. We further identified the operons and pathways of these essential genes and predicted the functions of these genes.
The numbers of essential genes in the different strains are distinct suggesting that although the genome of $M$. tuberculosis is highly conserved, variations exist among different strains. The differences lead to the various capacities of virulence, evolution, and immunogenic among M. tuberculosis strains. Therefore, the investigations on the difference among essential genes in different strains probably gain insight the new mechanism of pathogenesis, especially between the virulent stain (H37Rv) and avirulent stain (H37Ra).

In our study, there were about $40 \%$ operons having two or more essential genes. Some operons have as much as ten essential genes. In the pathway analysis, some pathways are consisted of as much as 50 essential genes. At present, there is no any experimental methods can perform the scanning of essential genes aspect for M. tuberculosis. In order to further verify whether these identified genes are essential genes, we used pathway analysis to found that if multiple essential genes are adjacent to each other and constitute known essential pathway, we highly suspected these genes identified are essential, which is critical for drug or vaccine development. Histidine metabolism pathway and peptidoglycan synthesis pathway were found in this study base on pathway enrichment analysis,most genes in these two pathways were essential genes and adjacent to each other. In this case, in-depth studies of above two 
pathways maybe provide more broad perspective for the new drug development.

Function analysis revealed that $61.79 \%$ of essential genes were categorized into virulence,intermediary metabolism/respiration,cell wall related and lipid metabolism, which are fundamental functions that exist in most bacteria species $[23,24]$, however, insertion sequences, phages and horizontal transfer genes (HTG) are also founded. The function of insertion sequence in $\mathrm{Myco-}$ bacterium tuberculosis are till obscure, and several literatures report that insertion sequences plays a vital role in the growth cycle, which are essential for the bacteria $[25,26]$. The PE/PPE family is M. tuberculosis-specific and is involved in M. tuberculosis infection and virulence. PE/PPE genes accounted for $10 \%$ of $M$. tuberculois genome. Several essential genes that are related to PE/ PPE family were also identified in this study, which plays an important role in cell wall synthesis [27].

\section{Conclusion}

In current study, we have identified the essential genes of $M$. tuberculosis using bibliometric approach at genomic level. The essential gene modules were further identified and analyzed.

\section{Additional file}

Additional file 1: Table S1. All essential genes collected with

Bioliometric approach.

\section{Abbreviations}

DOOR: Database of prOkaryotic OpeRons; KEGG: Kyoto Encyclopedia of Genes and Genome; UMP: Uridine monophosphate.

\section{Competing interests}

The authors declare that they have no competing interests.

\section{Authors' contributions}

Conceived and design: GW, FL. Data collection: JS, FW. Analyzed the data: $\mathrm{CW}, \mathrm{BL}, \mathrm{YZ}$. Wrote the paper: GX, GW. All authors read and approved the final manuscript.

\section{Acknowledgements}

This work was supported by the National Natural Science Foundation of China (81271897 and 81071424), National Basic Research Program of China (973 program, 2011CB512003), Specialized Research Fund for the Doctoral Program of Higher Education of China (20110061120093), China Postdoctoral Science Foundation (20110491311 and 2012 T50285), Foundation of Xinjiang Provincial Science \& Technology Department (201091148), Foundation of Jilin Provincial Health Department (2010Z034 and 2011Z049), Norman Bethune Program of Jilin University (2012219), Fundamental of Jilin University Basic Research Program (2012ZKF06)

\section{Author details}

${ }^{1}$ Key Laboratory of Zoonosis, Ministry of Education, Norman Bethune College of Medicine, Jilin University, Changchun, Jilin, China. ${ }^{2}$ The First Bethune Hospital of Jilin University, Changchun, Jilin, China.

Received: 28 April 2012 Accepted: 15 May 2013

Published: 20 May 2013
References

1. Dutta NK, Mehra S, Didier PJ, Roy CJ, Doyle LA, Alvarez X, Ratterree M, Be $N A$, Lamichhane $G$, Jain SK, et al: Genetic requirements for the survival of tubercle bacilli in primates. J Infect Dis 2010, 201(11):1743-1752.

2. Meena LS: Rajni: Survival mechanisms of pathogenic Mycobacterium tuberculosis H37Rv. FEBS J 2010, 277(11):2416-2427.

3. Cavusoglu C, Durmaz R, Bilgic A, Gunal S: Genotyping of rifampin-resistant Mycobacterium tuberculosis isolates from western Turkey. Ann Saudi Med 2004, 24(2):102-105.

4. Cohn DL, Bustreo F, Raviglione MC: Drug-resistant tuberculosis: review of the worldwide situation and the WHO/IUATLD Global Surveillance Project. International Union Against Tuberculosis and Lung Disease. Clin Infect Dis 1997, 24(Suppl 1):S121-S130

5. Wallengren K, Scano F, Nunn P, Margot B, Buthelezi SS, Williams B, Pym A, Samuel EY, Mirzayev F, Nkhoma W, et al: Drug-Resistant tuberculosis, KwaZulu-Natal, South Africa, 2001-2007. Emerg Infect Dis 2011 17(10):1913-1916

6. Gerdes S, Edwards R, Kubal M, Fonstein M, Stevens R, Osterman A: Essential genes on metabolic maps. Curr Opin Biotechnol 2006, 17(5):448-456.

7. Koonin EV: Comparative genomics, minimal gene-sets and the last universal common ancestor. Nat Rev Microbiol 2003, 1(2):127-136.

8. Hong-Geller E, Micheva-Viteva SN: Functional gene discovery using RNA interference-based genomic screens to combat pathogen infection. Curr Drug Discov Technol 2010, 7(2):86-94.

9. Awasthy D, Bharath S, Subbulakshmi V, Sharma U: Alanine racemase mutants of Mycobacterium tuberculosis require D-alanine for growth and are defective for survival in macrophages and mice. Microbiology 2011, 158(Pt 2):319-327.

10. Ta P, Buchmeier N, Newton GL, Rawat M, Fahey RC: Organic hydroperoxide resistance protein and ergothioneine compensate for loss of mycothiol in Mycobacterium smegmatis mutants. J Bacteriol 2011, 193(8):1981-1990.

11. Warnecke T, Hurst LD: Error prevention and mitigation as forces in the evolution of genes and genomes. Nat Rev Genet 2011, 12(12):875-881.

12. Bannantine JP, Stabel JR, Bayles DO, Geisbrecht BV: Characteristics of an extensive Mycobacterium avium subspecies paratuberculosis recombinant protein set. Protein Expr Purif 2010, 72(2):223-233.

13. Mao F, Dam P, Chou J, Olman V, Xu Y: DOOR: a database for prokaryotic operons. Nucleic Acids Res 2009, 37(Database issue):D459-D463.

14. Yin $Y$, Zhang $H$, Olman $V, X u Y$ : Genomic arrangement of bacterial operons is constrained by biological pathways encoded in the genome. Proc Natl Acad Sci U S A 2010, 107(14):6310-6315.

15. Zhang $H$, Yin $Y$, Olman $V$, Xu Y: Genomic arrangement of regulons in bacterial genomes. PLoS One 2012, 7(1):e29496.

16. Zhang XC, Huang DS, Li F: Cancer nursing research output and topics in the first decade of the 21 st century: results of a bibliometric and co-word cluster analysis. Asian Pac J Cancer Prev 2012, 12(8):2055-2058.

17. Spangler ML, Robbins KR, Bertrand JK, Macneil M, Rekaya R: Ant colony optimization as a method for strategic genotype sampling. Anim Genet 2009, 40(3):308-314.

18. Chen W, Liao B, Zhu W, Xiang X: Multiple sequence alignment algorithm based on a dispersion graph and ant colony algorithm. J Comput Chem 2009, 30(13):2031-2038.

19. Cole ST, Brosch R, Parkhill J, Garnier T, Churcher C, Harris D, Gordon SV, Eiglmeier K, Gas S, Barry CE III, et al: Deciphering the biology of Mycobacterium tuberculosis from the complete genome sequence. Nature 1998, 393(6685):537-544.

20. Alonso H, Aguilo JI, Samper S, Caminero JA, Campos-Herrero MI, Gicquel B, Brosch R, Martin C, Otal I: Deciphering the role of IS6110 in a highly transmissible Mycobacterium tuberculosis Beijing strain, GC1237. Tuberculosis (Edinb) 2011, 91(2):117-126.

21. Due AV, Kuper J, Geerlof A, von Kries JP, Wilmanns M: Bisubstrate specificity in histidine/tryptophan biosynthesis isomerase from Mycobacterium tuberculosis by active site metamorphosis. Proc Natl Acad Sci U S A 2011, 108(9):3554-3559.

22. Carrey EA, Dietz C, Glubb DM, Loffler M, Lucocq JM, Watson PF: Detection and location of the enzymes of de novo pyrimidine biosynthesis in mammalian spermatozoa. Reproduction 2002, 123(6):757-768.

23. Hotter GS, Collins DM: Mycobacterium bovis lipids: virulence and vaccines. Vet Microbio/ 2011, 151(1-2):91-98 
24. Salaemae W, Azhar A, Booker GW, Polyak SW: Biotin biosynthesis in Mycobacterium tuberculosis: physiology, biochemistry and molecular intervention. Protein Cell 2011, 2(9):691-695.

25. Sassetti $\mathrm{CM}$, Boyd DH, Rubin EJ: Genes required for mycobacterial growth defined by high density mutagenesis. Mol Microbiol 2003, 48(1):77-84.

26. Rahman MS, Ceraul SM, Dreher-Lesnick SM, Beier MS, Azad AF: The IspA gene, encoding the type II signal peptidase of Rickettsia typhi: transcriptional and functional analysis. J Bacteriol 2007, 189(2):336-341.

27. Gey van Pittius NC, Sampson SL, Lee H, Kim Y, van Helden PD, Warren RM: Evolution and expansion of the Mycobacterium tuberculosis PE and PPE multigene families and their association with the duplication of the ESAT-6 (esx) gene cluster regions. BMC Evol Biol 2006, 6:95.

doi:10.1186/1471-2334-13-227

Cite this article as: Xu et al:: High-throughput screen of essential gene modules in Mycobacterium tuberculosis: a bibliometric approach. BMC Infectious Diseases 2013 13:227.

\section{Submit your next manuscript to BioMed Central and take full advantage of:}

- Convenient online submission

- Thorough peer review

- No space constraints or color figure charges

- Immediate publication on acceptance

- Inclusion in PubMed, CAS, Scopus and Google Scholar

- Research which is freely available for redistribution 